\title{
Phase I dose-escalation study of long-acting pasireotide in patients with neuroendocrine tumors
}

\author{
James CYao' \\ Jennifer A Chan ${ }^{2}$ \\ Alain C Mita ${ }^{3}$ \\ Madan G Kundu ${ }^{4}$ \\ Karina Hermosillo \\ Reséndiz ${ }^{4}$ \\ $\mathrm{Ke} \mathrm{Hu}{ }^{4}$ \\ Shoba Ravichandran ${ }^{4}$ \\ Jonathan R Strosberg ${ }^{5}$ \\ Edward MWolin ${ }^{6}$ \\ 'GI Medical Oncology, The University \\ of Texas MD Anderson Cancer \\ Center, Houston, TX, ${ }^{2}$ Gastrointestinal \\ Cancer Center, Dana-Farber Cancer \\ Institute, Boston, MA, ${ }^{3}$ Experimental \\ Therapeutics, Cedars-Sinai Medical \\ Center, Los Angeles, CA, ${ }^{4}$ Oncology, \\ Novartis Pharmaceuticals Corporation, \\ East Hanover, NJ, ${ }^{5}$ Department of \\ Gastrointestinal Oncology, H. Lee \\ Moffitt Cancer Center and Research \\ Institute, Tampa, FL, ${ }^{6}$ Oncology, \\ Montefiore Einstein Center for Cancer \\ Care, Bronx, NY, USA
}

Correspondence: James C Yao GI Medical Oncology, The University of Texas MD Anderson Cancer Center, I5I 5 Holcombe Boulevard, Unit 0426 , Houston, TX 77030, USA

$\mathrm{Tel}+\mathrm{I} 7 \mid 37922828$

Fax + I 7135630539

Email jyao@mdanderson.org
This article was published in the following Dove Press journal:

OncoTargets and Therapy

27 June 2017

Number of times this article has been viewed

Abstract: This phase I study aimed at determining the maximum tolerated dose (MTD) and characterizing the safety, tolerability, pharmacokinetics (PKs), and efficacy of pasireotide in patients with advanced neuroendocrine tumors (NETs). Patients were enrolled in two phases: dose-escalation phase (to determine the MTD) at a starting dose of $80 \mathrm{mg}$ pasireotide longacting release (LAR) i.m. followed by a dose-expansion phase (to evaluate safety and preliminary efficacy). Associations between PK/pharmacodynamic parameters and clinical outcomes were evaluated using linear regression analysis. A total of 29 patients were treated with $80 \mathrm{mg}$ $(\mathrm{n}=13)$ and $120 \mathrm{mg}(\mathrm{n}=16)$ doses. Most common primary tumor sites included small intestine (44.8\%), pancreas (24.1\%), and lung (17.2\%). No protocol-defined dose-limiting toxicities were observed in the study; however, in post hoc analysis, a higher incidence of bradycardia (heart rate $[\mathrm{HR}]<40$ beats per minute $[\mathrm{bpm}])$ was observed with $120 \mathrm{mg}(31.3 \%)$ vs $80 \mathrm{mg}(0 \%)$. Two partial responses (PRs) were observed, both in the $120 \mathrm{mg}$ dose cohort. Pasireotide concentrations correlated with tumor shrinkage, although the association was not statistically significant $(P=0.08)$. Among the biomarkers analyzed, insulin-like growth factor 1 (IGF-1) showed a decreasing trend with increasing pasireotide concentration, while chromogranin $\mathrm{A}$ $(\mathrm{CgA})$ and neuron-specific enolase (NSE) levels did not show any dose-response relationship. The most common adverse events in any dose group were hyperglycemia, fatigue, and nausea. MTD was defined at $120 \mathrm{mg}$ for pasireotide LAR in patients with advanced NETs. Although objective radiographic responses were rarely observed with somatostatin analogs, two PRs were observed among 16 patients in the $120 \mathrm{mg}$ cohort. Bradycardia (HR $<40 \mathrm{bpm}$ ) appears to be a dose-limiting effect; however, the mechanism and clinical significance are uncertain. This study was registered with clinicaltrials.gov (NCT01364415).

Keywords: pharmacokinetics, pharmacodynamics, MTD, Bayesian logistic regression model, dose escalation with overdose control

\section{Introduction}

Somatostatin analogs (SSAs), such as octreotide long-acting release (LAR) and lanreotide autogel, are the standard of care for treatment of symptoms resulting from hormonal secretions in functioning neuroendocrine tumors (NETs). ${ }^{1-4}$ Although the efficacy of SSAs in symptom control for NETs has been well established, ${ }^{4,5}$ the role of SSAs in tumor control has been only recently elucidated. Limited data from prospective studies exist on the efficacy and safety of SSAs when combined with targeted agents. Antitumor activity of SSAs in NETs was first demonstrated in the placebo-controlled, double-blind, randomized phase III PROMID study in which octreotide LAR showed a clinically meaningful increase in time to tumor progression compared with placebo in 
patients with metastatic midgut NETs. ${ }^{6}$ In the recent phase III CLARINET study, lanreotide autogel, another SSA with a somatostatin receptor type $2\left(\mathrm{sst}_{2}\right)$ affinity profile similar to that of octreotide, demonstrated progression-free survival (PFS) benefit in patients with nonfunctional enteropancreatic NETs and has been recently approved for clinical use in patients with advanced enteropancreatic NETs. ${ }^{7}$ A literature review conducted by Berardi et $\mathrm{al}^{8}$ on treatment strategy for NETs concluded that SSAs and targeted therapies should be considered as first-line options for the treatment of Grade 1-Grade 2 advanced pancreatic NETs (pNETs).

SSAs act via interaction with sst of which five subtypes $\left(\mathrm{sst}_{1}-\mathrm{sst}_{5}\right)$ with clinical activity have been described in gastroenteropancreatic NETs (GEP-NETs). ${ }^{9}$ Octreotide and lanreotide exert their activity primarily via binding to $\mathrm{sst}_{2}{ }^{9-11}$ However, tumor cells may become resistant, leading to symptomatic and/or radiographic progression. Potential mechanisms of resistance include internalization of $\mathrm{sst}_{2}$, downregulation of $\mathrm{sst}_{2}$, and overexpression of other sst. ${ }^{9,12-15}$

Pasireotide, a second-generation multireceptor-targeted SSA, has a broader binding profile and higher binding affinity for sst $_{1-3}$ and sst $_{5}$ than those of octreotide and lanreotide (Figure 1). ${ }^{16,17}$ Pasireotide is available as short-acting pasireotide for subcutaneous (SC) administration with twice-daily administration schedule and the LAR formulation for intramuscular (IM) injection administered once every 28 days with similar pharmacokinetics (PKs)/pharmacodynamics and safety profile. ${ }^{18}$ In an exploratory analysis from a phase III study in patients with advanced carcinoid syndrome refractory to octreotide LAR, pasireotide LAR $60 \mathrm{mg}$ showed encouraging antitumor activity compared with octreotide LAR 30 mg. ${ }^{19}$ Median (95\% CI) PFS was 11.8 months (11.0-not reached) with pasireotide LAR vs 6.8 months (5.6-not reached) with octreotide LAR (hazard ratio, 0.46; 95\% CI, 0.20-0.98; two-sided $P=0.045)$. Tumor control rate at month 6 was $62.7 \%$ with pasireotide and $46.2 \%$ with octreotide (odds ratio, 1.96; 95\% CI, 0.89-4.32; $P=0.09$ ). A phase II study of first-line standard-dose pasireotide LAR (60 mg every 4 weeks) in a more heterogeneous cohort of metastatic NETs demonstrated a median PFS of 11 months. ${ }^{20}$

The phase II COOPERATE-2 study was conducted to assess the efficacy and safety of pasireotide (LAR; $60 \mathrm{mg} / 28$ days, intramuscularly) in combination with everolimus (10 mg/day, orally) in patients with advanced, welldifferentiated, progressive pNETs. The study failed to show the benefit of combining pasireotide LAR $60 \mathrm{mg}$ with everolimus in terms of prolongation of PFS. ${ }^{21}$ Additionally, the maximum tolerated dose (MTD) of pasireotide has been unknown, and clinical outcomes associated with high doses of this drug have not been explored. Therefore, this phase I study (NCT01364415) was designed to determine the MTD of pasireotide LAR and characterize the safety, tolerability, and antitumor efficacy trends in patients with advanced NETs with a starting dose of $80 \mathrm{mg} / 28$ days. The study further evaluated the PKs of pasireotide LAR and its effects on biochemical and tumor biomarkers specific for NETs in this patient population.

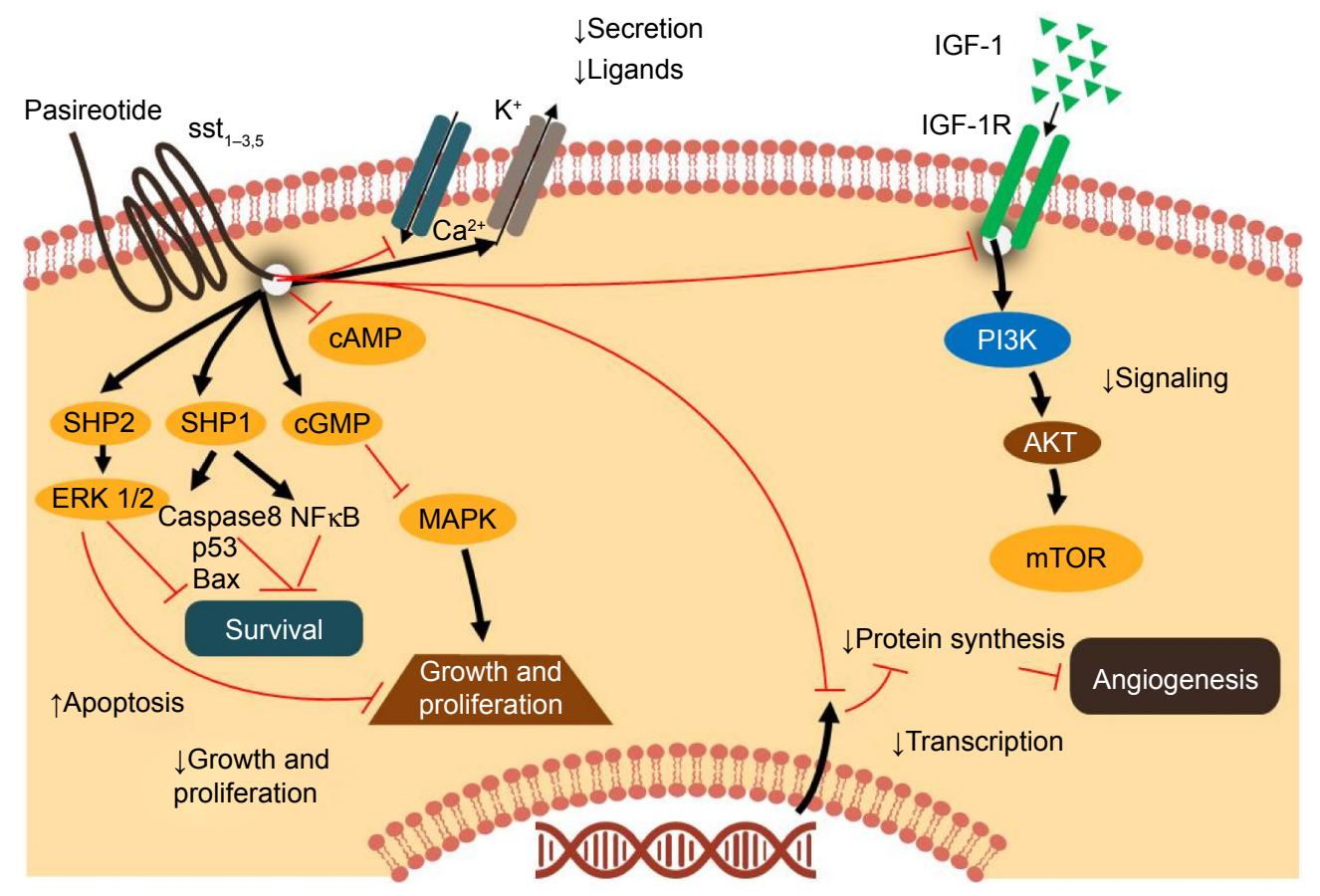

Figure I Postulated mechanism of action of pasireotide. 


\section{Methods \\ Study design}

This phase I, multi-center, open-label, dose-escalation study investigated the safety and tolerability, PKs/ pharmacodynamics, and preliminary efficacy of pasireotide LAR in patients with advanced NETs. The study consisted of two phases: a dose-escalation phase ( $\mathrm{n}=3-6$ patients in each cohort) and a dose-expansion phase ( $\mathrm{n} \geq 12$ patients). The starting dose of pasireotide LAR in the dose-escalation phase was $80 \mathrm{mg} / 28$ days, which was administered by IM injection. Additional doses were selected with the assistance of the two-parameter Bayesian logistic regression model (BLRM) using the dose escalation with overdose control (EWOC) principle in multiples of $20 \mathrm{mg}$. Intra-patient dose escalation was not allowed in the study; however, dose deescalation was permitted. The primary objective of the study was to determine the MTD of pasireotide LAR in patients with advanced NETs. A key secondary objective was to characterize the safety and tolerability of pasireotide LAR in this patient population. Other end points included assessment of PKs/pharmacodynamics and preliminary evaluation of the antitumor activity of high-dose pasireotide LAR in NETs.

Patients could discontinue the study treatment prematurely due to adverse events (AEs), abnormal laboratory values or test procedure results, protocol deviation, consent withdrawal, loss to follow-up, administrative problems, death, or disease progression.

\section{Study population}

Adults (aged $\geq 18$ years) with histologically confirmed advanced (unresectable and/or metastatic), well-differentiated, or moderately differentiated (low or intermediate grade) NETs with documented disease progression in the prior 12 months, independent of primary tumor location and functional status, were enrolled in the study. A key exclusion criterion included patients with baseline glycosylated hemoglobin $\left(\mathrm{HbA}_{1 \mathrm{c}}\right)>7.0 \%$.

\section{MTD/dose-limiting toxicity (DLT) analysis}

MTD was defined as the highest dose with expected DLT in $\leq 33 \%$ of the treated patients in the first two treatment cycles. A treatment cycle was typically 28 days long, starting with each injection of pasireotide LAR and ending right before the next injection. Patients who received two injections of pasireotide LAR and underwent sufficient safety evaluation or who experienced DLT within the first two treatment cycles were considered evaluable for DLT (dosedetermining set). Dose-escalation decisions were taken based on the observed number of DLTs (via BLRM) ${ }^{22}$ and observed safety profile of the patients in the dose-determining set. Other safety and efficacy analyses included all patients who received one or more doses of study medication; patients were grouped according to the first dose received. AEs and laboratory abnormalities were assessed according to the Medical Dictionary for Regulatory Activities (MedDRA) version 18.0 and Common Terminology Criteria for Adverse Events (CTCAE) version 3.0, respectively.

\section{PKs and biomarker analysis}

Descriptive statistics and graphical depiction for pasireotide plasma concentrations were performed for PK analysis. $\mathrm{PK} /$ pharmacodynamic analysis evaluated the relationship between pasireotide plasma concentrations and levels of efficacy and safety markers. Biomarkers for efficacy included insulin-like growth factor 1 (IGF-1), glucagon and NETspecific tumor biomarker chromogranin $\mathrm{A}(\mathrm{CgA})$, and neuronspecific enolase (NSE). Among safety markers, heart rate (HR) was assessed using 24 hours Holter monitoring assessment on Cycle 1 (C1) Day 1 and Cycle 2 (C2) Day 1 in all the patients. Analyses of bradycardia were performed by combining HR data from assessment of vital signs, 12-lead electrocardiograms (ECGs), and 24-hour Holter ECGs with bradycardia defined as minimum $\mathrm{HR}<40$ beats per minute (bpm).

\section{Tumor evaluation}

Tumor evaluation was based on Response Evaluation Criteria In Solid Tumors (RECIST) 1.0 by site investigator; 95\% CIs were based on the Clopper-Pearson method. It was not required for tumor assessment to be blinded in this study.

The study was approved by the respective institutional review boards of participating sites (Cedars-Sinai Cancer Center, Los Angeles; Dana-Farber Cancer Institute, Boston; H. Lee Moffitt Cancer Center, Tampa; and MD Anderson Cancer Center, Houston), and all patients provided written informed consent to participate.

\section{Results}

\section{Patient characteristics}

As of July 2015, a total of 29 patients, 15 patients in the doseescalation phase and 14 patients in the dose-expansion phase, were treated with pasireotide LAR in five successive cohorts. In the dose-escalation phase, the initial dose was $80 \mathrm{mg}$ in Cohort $1(\mathrm{n}=6)$, and the dose was then escalated to $120 \mathrm{mg}$ in Cohort $2(\mathrm{n}=4)$. The dose of $120 \mathrm{mg}$ was maintained in Cohort $3(n=5)$. The dose-expansion phase started with $120 \mathrm{mg}$ in cohort $4(\mathrm{n}=7)$. However, after safety evaluation, the dose was reduced to $80 \mathrm{mg}$ in Cohort $5(\mathrm{n}=7)$. Overall, 13 patients received the $80 \mathrm{mg}$ dose and 16 patients were 
treated with the $120 \mathrm{mg}$ dose. In the $80 \mathrm{mg}$ dose group, dose de-escalation (from 80 to $60 \mathrm{mg}$ ) was performed in one patient due to AEs. Primary tumor sites included small intestine $(45 \% ; 13 / 29)$, pancreas $(24 \% ; 7 / 29)$, lung $(17 \% ; 5 / 29)$, colon $(3 \% ; 1 / 29)$, rectum $(3 \% ; 1 / 29)$, and unknown $(7 \%$; $2 / 29$ ). Most common sites of metastases included liver in $83 \%(24 / 29)$ and lung in 31\% (9/29) of patients. Median time since initial diagnosis of primary site was 50 months (range, 1-218 months). Most patients had undergone prior treatments, including prior surgery, 97\% (28/29), and prior radiotherapy, $21 \%(6 / 29)$. A total of $38 \%(11 / 29)$ of patients received systemic treatment beyond SSAs. Most patients $(90 \% ; 26 / 29)$ received prior SSA therapy. Detailed patient characteristics are listed in Table 1.

Table I Patient baseline characteristics

\begin{tabular}{|c|c|c|c|}
\hline Patient characteristics & $\begin{array}{l}\text { Pasireotide LAR } \\
80 \mathrm{mg}(\mathrm{n}=13)\end{array}$ & $\begin{array}{l}\text { Pasireotide LAR } \\
120 \mathrm{mg}(\mathrm{n}=16)\end{array}$ & $\begin{array}{l}\text { All patients } \\
(\mathrm{N}=29)\end{array}$ \\
\hline \multicolumn{4}{|l|}{ Age (years) } \\
\hline Median (range, min-max) & $58.0(42-78)$ & $60.0(44-76)$ & $58.0(42-78)$ \\
\hline \multicolumn{4}{|l|}{ Age category (years), n (\%) } \\
\hline$<65$ & $10(76.9)$ & $10(62.5)$ & $20(69.0)$ \\
\hline$\geq 65$ & $3(23.1)$ & $6(37.5)$ & $9(31.0)$ \\
\hline \multicolumn{4}{|l|}{ Sex, n (\%) } \\
\hline Male & $4(30.8)$ & $5(31.3)$ & $9(31.0)$ \\
\hline Female & $9(69.2)$ & II (68.8) & $20(69.0)$ \\
\hline \multicolumn{4}{|l|}{ Race, n (\%) } \\
\hline Caucasian & II (84.6) & $13(81.3)$ & $24(82.8)$ \\
\hline Black & $2(15.4)$ & I (6.3) & $3(10.3)$ \\
\hline Asian & 0 & I (6.3) & I (3.4) \\
\hline Other & 0 & I (6.3) & I (3.4) \\
\hline \multicolumn{4}{|l|}{ Ethnicity, n (\%) } \\
\hline Mixed ethnicity & 0 & $\mathrm{I}(6.3)$ & I (3.4) \\
\hline Others & $13(100.0)$ & $15(93.8)$ & $28(96.6)$ \\
\hline \multicolumn{4}{|l|}{ Body mass index $\left(\mathrm{kg} / \mathrm{m}^{2}\right)$} \\
\hline Median (range, min-max) & $27.10(21.4-40.7)$ & $25.90(\mid 8.6-45.1)$ & $26.10(\mid 8.6-45.1)$ \\
\hline \multicolumn{4}{|c|}{ WHO performance status, n (\%) } \\
\hline No restrictions & $6(46.2)$ & $8(50.0)$ & I4 (48.3) \\
\hline Only light work & $7(53.8)$ & $8(50.0)$ & $15(5 \mid .7)$ \\
\hline \multicolumn{4}{|l|}{ Histologic grade, $n(\%)$} \\
\hline Well differentiated & II (84.6) & $12(75.0)$ & $23(79.3)$ \\
\hline Moderately differentiated & $2(15.4)$ & $4(25.0)$ & $6(20.7)$ \\
\hline \multicolumn{4}{|l|}{ Primary site of cancer, $\mathrm{n}(\%)$} \\
\hline Lung & 0 & $4(25.0)$ & $4(13.8)$ \\
\hline Pancreas & $2(15.4)$ & $5(31.3)$ & $7(24.1)$ \\
\hline Small intestine & $6(46.2)$ & $7(43.8)$ & $13(44.8)$ \\
\hline Colon & I (7.7) & 0 & I (3.4) \\
\hline Rectum & I (7.7) & 0 & I (3.4) \\
\hline Others & $3(23.1)$ & 0 & $3(10.3)$ \\
\hline \multicolumn{4}{|c|}{ Current extent of disease*, $\mathrm{n}(\%)-$ metastatic sites } \\
\hline Liver & II (84.6) & $13(81.3)$ & $24(82.8)$ \\
\hline Lung & $2(15.4)$ & $7(43.8)$ & $9(31.0)$ \\
\hline Peritoneum & $3(23.1)$ & $2(12.5)$ & $5(17.2)$ \\
\hline Omentum & $3(23.1)$ & I (6.3) & $4(13.8)$ \\
\hline Pancreas & $2(15.4)$ & $\mathrm{I}(6.3)$ & $3(10.3)$ \\
\hline Small bowel & $2(15.4)$ & I (6.3) & $3(10.3)$ \\
\hline Ascites (malignant) & I (7.7) & $2(12.5)$ & $3(10.3)$ \\
\hline Bone & I (7.7) & $2(12.5)$ & $3(10.3)$ \\
\hline \multicolumn{4}{|l|}{ Prior therapies, n (\%) } \\
\hline Any prior therapy & $13(100.0)$ & 15 (93.8) & $28(96.6)$ \\
\hline Surgery & $13(100.0)$ & $15(93.8)$ & $28(96.6)$ \\
\hline Radiotherapy & $2(I 5.4)$ & $4(25.0)$ & $6(20.7)$ \\
\hline Prior SSA therapy & $12(92.3)$ & $14(87.5)$ & $26(89.7)$ \\
\hline
\end{tabular}

Note: *Reported for $>10 \%$ patients.

Abbreviations: LAR, long-acting release; WHO, World Health Organization; SSA, somatostatin analog. 
Table 2 Primary reasons for treatment discontinuation

\begin{tabular}{|c|c|c|c|}
\hline $\begin{array}{l}\text { Primary reasons for end } \\
\text { of treatment }\end{array}$ & $\begin{array}{l}\text { Pasireotide LAR } \\
80 \mathrm{mg}(\mathrm{n}=\mid 3), \mathrm{n}(\%)\end{array}$ & $\begin{array}{l}\text { Pasireotide LAR } \\
\text { I } 20 \text { mg (n=|6), n (\%) }\end{array}$ & $\begin{array}{l}\text { All patients } \\
(\mathrm{N}=29), \mathrm{n}(\%)\end{array}$ \\
\hline Disease progression & $7(53.8)$ & $6(37.5)$ & $13(44.8)$ \\
\hline AEs & $4(30.8)$ & $4(25.0)$ & $8(27.6)$ \\
\hline Subject withdrew consent & 0 & I (6.3) & I (3.4) \\
\hline Death & 0 & I (6.3) & I (3.4) \\
\hline Protocol deviation & I (7.7) & 0 & I (3.4) \\
\hline
\end{tabular}

Abbreviations: LAR, long-acting release; AEs, adverse events.

\section{Patient disposition}

At the time of data cutoff (July 2015), one of 13 patients was still undergoing treatment with the $80 \mathrm{mg}$ dose and four patients of 16 were undergoing treatment with the $120 \mathrm{mg}$ dose. The median duration of follow-up was 6 months in the $80 \mathrm{mg}$ dose group and 9 months in the $120 \mathrm{mg}$ dose group from enrollment to data cutoff date. The overall median duration of exposure to study treatment was 8.7 months with a median of 6.7 months in the $80 \mathrm{mg}$ group and 10.1 months in the $120 \mathrm{mg}$ dose group. The primary reason for treatment discontinuation was disease progression in the majority of the patients (Table 2). In the pasireotide $80 \mathrm{mg}$ group, four patients discontinued the study treatment due to AEs (leukocytosis, diarrhea, fatigue, lipase increase, and weight decrease). Of these AEs, leukocytosis and lipase increase were Grade 3/4 AEs; diarrhea and lipase increase were suspected to be drug-related AEs. In the $120 \mathrm{mg}$ group, four patients discontinued the study treatment due to AEs (atrioventricular block complete, performance status decrease, blood creatinine increase, gamma-glutamyl transferase increase, and hyperglycemia). Of these AEs, atrioventricular block complete, performance status decrease, and gamma-glutamyl transferase increase were Grade 3/4 AEs; gamma-glutamyl transferase increase and hyperglycemia were suspected to be drug related.

\section{MTD/DLTs}

A total of 15 patients were recruited and treated in three dose cohorts in the dose-escalation phase. There was no protocoldefined DLTs reported in the study. In a post hoc analysis of the safety data from dose-escalation cohort and one cohort (the $120 \mathrm{mg}$ cohort) in the dose-expansion phase, greater incidence of bradycardia (HR $<40 \mathrm{bpm}$ ) was identified in the $120 \mathrm{mg}$ group compared to that in the $80 \mathrm{mg}$ group. At the time of cutoff, considering both the dose-escalation and dose-expansion cohorts, the incidence of bradycardia with HR $<40 \mathrm{bpm}$ was $31 \%(5 / 16)$ in the $120 \mathrm{mg}$ group and $0 \%(0 / 13)$ in the $80 \mathrm{mg}$ group based on Holter assessment.
Subsequently, $120 \mathrm{mg}$ was considered to be the MTD for pasireotide LAR in patients with advanced NETs.

\section{Safety}

The safety set included all patients $(\mathrm{N}=29)$ from the study. AEs of any grade were seen in $92 \%$ of patients who received the $80 \mathrm{mg}$ dose and $100 \%$ of patients who received the $120 \mathrm{mg}$ dose. AEs leading to discontinuation with suspected drug relationship were seen in two (15\%) and two (13\%) patients in the $80 \mathrm{mg}$ and $120 \mathrm{mg}$ dose groups, respectively. Grade 3/4 AEs suspected to be drug related were seen in two $(15 \%)$ and five (31\%) patients who received $80 \mathrm{mg}$ and $120 \mathrm{mg}$ doses, respectively.

Most common AEs of any grade regardless of drug relationship were hyperglycemia, diarrhea, and fatigue in both the $80 \mathrm{mg}$ and $120 \mathrm{mg}$ dose groups (Table 3 ). There were two deaths reported in the study, including one on-treatment death (within 56 days of last treatment). The on-treatment death occurred in a patient treated with the $120 \mathrm{mg}$ dose who died 25 days after the end of treatment due to hepatorenal failure; this was considered by the investigator to be unrelated to the study drug. One patient in the $80 \mathrm{mg}$ group died 345 days after the end of treatment due to disease progression in the posttreatment follow-up phase.

\section{Efficacy}

PFS by local radiological review

PFS events were reported in 54\% (7/13) of the patients in the $80 \mathrm{mg}$ arm and $50 \%(8 / 16)$ of patients in the $120 \mathrm{mg}$ arm. The median PFS $(95 \% \mathrm{CI})$ was 8.3 months $(2.7$, not estimable [NE]) and 10.8 months $(6.2, \mathrm{NE})$ in the $80 \mathrm{mg}$ dose group and $120 \mathrm{mg}$ dose group, respectively (Figure 2).

\section{Best overall response as per local radiological review} Two partial responses (PRs) were observed as best overall response in the 16 patients receiving the $120 \mathrm{mg}$ dose. Both these patients had pancreas as their primary site of tumor. One of the patients (58 years of age; female) had a 
Table 3 AEs regardless of study drug relationship ( $\geq 15 \%$ in the $120 \mathrm{mg}$ dose)

\begin{tabular}{|c|c|c|c|c|c|c|}
\hline \multirow[b]{2}{*}{ AEs, n (\%) } & \multicolumn{2}{|c|}{$\begin{array}{l}\text { Pasireotide LAR } 80 \mathrm{mg} \\
(\mathrm{n}=13)\end{array}$} & \multicolumn{2}{|c|}{$\begin{array}{l}\text { Pasireotide LAR I } 20 \mathrm{mg} \\
(\mathrm{n}=16)\end{array}$} & \multicolumn{2}{|c|}{$\begin{array}{l}\text { All patients } \\
(\mathrm{N}=\mathbf{2 9})\end{array}$} \\
\hline & All grade & Grade 3/4 & All grade & Grade 3/4 & All grade & Grade $3 / 4$ \\
\hline Total & $12(92.3)$ & $9(69.2)$ & $16(100)$ & II (68.8) & $28(96.6)$ & $20(69.0)$ \\
\hline Hyperglycemia & $10(76.9)$ & $2(15.4)$ & $13(81.3)$ & $I(6.3)$ & $23(79.3)$ & $3(10.3)$ \\
\hline Diarrhea & $4(30.8)$ & 0 & $8(50.0)$ & $\mathrm{I}(6.3)$ & $12(4 \mid .4)$ & I (3.4) \\
\hline Fatigue & $7(53.8)$ & 0 & $8(50.0)$ & 0 & I5 (5 I.7) & 0 \\
\hline Abdominal pain & $6(46.2)$ & $\mathrm{I}(7.7)$ & $6(37.5)$ & 0 & $12(4 \mid .4)$ & I (3.4) \\
\hline Dizziness & $2(15.4)$ & 0 & $6(37.5)$ & 0 & $8(27.6)$ & 0 \\
\hline Nausea & $7(53.8)$ & 0 & $5(31.3)$ & 0 & $12(4 \mid .4)$ & 0 \\
\hline Upper respiratory tract infection & I (7.7) & 0 & $5(31.3)$ & 0 & $6(20.7)$ & 0 \\
\hline Abdominal pain upper & 0 & 0 & $3(18.8)$ & 0 & $3(10.3)$ & 0 \\
\hline Anxiety & 0 & 0 & $3(18.8)$ & 0 & $3(10.3)$ & 0 \\
\hline Blood alkaline phosphatase increase & $2(15.4)$ & I (7.7) & $3(18.8)$ & 0 & $5(17.2)$ & I (3.4) \\
\hline Constipation & $4(30.8)$ & 0 & $3(18.8)$ & 0 & $7(24.1)$ & 0 \\
\hline Flatulence & I (7.7) & 0 & $3(18.8)$ & 0 & $4(13.8)$ & 0 \\
\hline Flushing & I (7.7) & 0 & $3(18.8)$ & 0 & $4(13.8)$ & 0 \\
\hline Hypertriglyceridemia & $3(23.1)$ & 0 & $3(18.8)$ & 0 & $6(20.7)$ & 0 \\
\hline Hypoglycemia & I (7.7) & 0 & $3(18.8)$ & $\mathrm{I}(6.3)$ & $4(13.8)$ & I (3.4) \\
\hline Edema peripheral & $3(23.1)$ & 0 & $3(18.8)$ & 0 & $6(20.7)$ & 0 \\
\hline Pyrexia & 0 & 0 & $3(18.8)$ & I (6.3) & $3(10.3)$ & I (3.4) \\
\hline
\end{tabular}

Note: AEs with start date beyond 56 days from last dosing have been excluded.

Abbreviations: $A E$, adverse event; LAR, long-acting release.

well-differentiated tumor and mediastinum diaphragmatic lymph node metastases; the second patient (44 years of age; female) had a moderately differentiated tumor and liver metastases. In these patients, PRs were reported from Day 168 and Day 198, respectively, and in both patients, PRs were confirmed on subsequent visits. No complete response (CR) was seen in either dose group. Most patients ( $>75 \%)$ had stable disease (SD) in both dose groups. Disease control rate (DCR; CR, PR, or SD) was $77 \%$ (95\% CI, 46\%, 95\%) in the $80 \mathrm{mg}$ group and $94 \%(95 \% \mathrm{CI}, 70 \%, 100 \%)$ in the $120 \mathrm{mg}$ group (Table 4).

\section{Tumor analysis}

The mean percentage change in tumor size (standard deviation) was $1.6 \%( \pm 9.38 \%)$ in the $80 \mathrm{mg}$ group and $-10.8 \%$ $( \pm 30 \%)$ in the $120 \mathrm{mg}$ group. The median percentage change in tumor size was $-2.7 \%$ and $3.5 \%$ in the $80 \mathrm{mg}$ and $120 \mathrm{mg}$ groups, respectively (two-sided $P$-value $=0.609$, as per exact Wilcoxon two-sample test).

\section{PKs/pharmacodynamics}

The PK profiles of pasireotide LAR $80 \mathrm{mg}$ and $120 \mathrm{mg}$ doses are shown in Figure 3A. Day 1 pre-dose concentrations

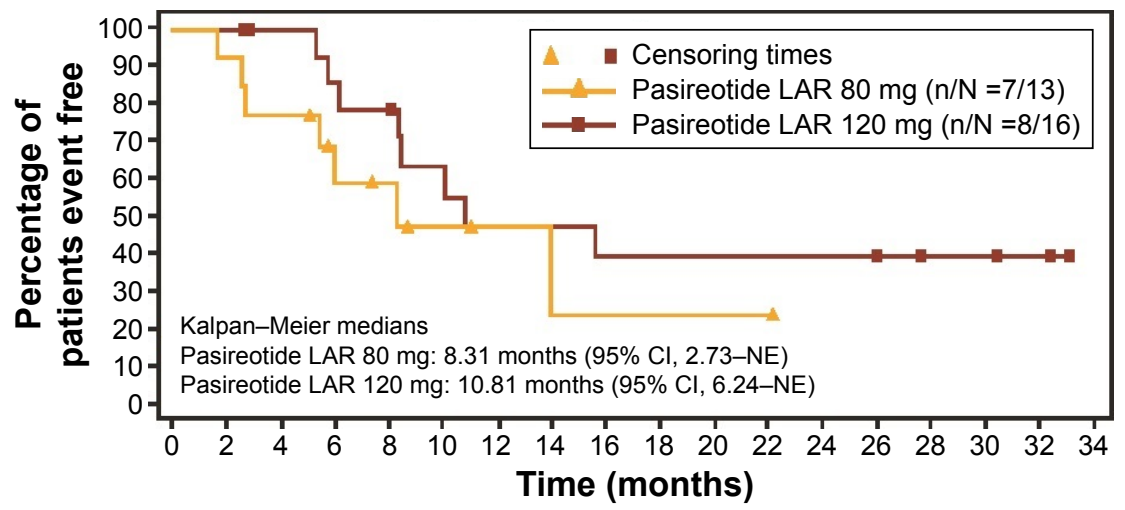

No of patients still at risk

$\begin{array}{llllllllllllllllll}\text { Pasireotide } & 13 & 12 & 10 & 7 & 5 & 3 & 2 & 2 & 1 & 1 & 1 & 1 & 0 & 0 & 0 & 0 & 0 \\ \text { LAR } 80 \mathrm{mg} & & & & & & & & & & & & & & & \\ \begin{array}{l}\text { Pasireotide } \\ \text { LAR } 16\end{array} & 16 & 14 & 12 & 11 & 8 & 6 & 6 & 5 & 5 & 5 & 5 & 5 & 5 & 3 & 3 & 2\end{array}$

Figure 2 Kaplan-Meier estimates of PFS by local radiological review.

Abbreviations: $\mathrm{Cl}$, confidence interval; NE, not estimable; PFS, progression-free survival; LAR, long-acting release. 
Table 4 Best overall response and DCR

\begin{tabular}{|c|c|c|}
\hline Overall response & $\begin{array}{l}\text { Pasireotide LAR } \\
80 \text { mg (n=13), n (\%) }\end{array}$ & $\begin{array}{l}\text { Pasireotide LAR } \\
\text { I } 20 \mathrm{mg}(\mathrm{n}=16), \mathrm{n}(\%)\end{array}$ \\
\hline \multicolumn{3}{|l|}{ Best overall response* } \\
\hline$C R$ & 0 & 0 \\
\hline PR & 0 & $2(12.5)$ \\
\hline SD & $10(76.9)$ & $13(8 \mid .3)$ \\
\hline PD & $3(23.1)$ & 0 \\
\hline Unknown** & 0 & I (6.3) \\
\hline ORR $\$, 95 \% \mathrm{Cl}$ for ORR & $0,(0,24.7)$ & 2 (I2.5\%), (1.6, 38.4) \\
\hline $\mathrm{DCR}^{\#}, 95 \% \mathrm{Cl}$ for $\mathrm{DCR}$ & 10 (76.9\%), $(46.2,95.0)$ & 15 (93.8\%), (69.8, 99.8) \\
\hline
\end{tabular}

Notes: *Tumor evaluation is based on RECIST 1.0. 95\% Cls are based on the Clopper-Pearson method. **Different methods were used for baseline (MRI) and post-baseline tumor assessment (spiral CT) in one patient, thus categorized as unknown. ${ }^{\$} O R R: C R+P R$. "DCR: CR+PR+SD.

Abbreviations: DCR, disease control rate; LAR, long-acting release; CR, complete response; PR, partial response; SD, stable disease; PD, progressive disease; ORR, overall response rate; MRI, magnetic resonance imaging; $\mathrm{CT}$, computed tomography; $\mathrm{Cl}$, confidence interval; RECIST, Response Evaluation Criteria In Solid Tumors.

on $\mathrm{C} 2$ through Cycle 12 (C12) represent $C_{\min }$ concentrations; day 22 concentration from the $\mathrm{C} 1$ represents the $C_{\max }$ concentration (mean $\pm \mathrm{SD}: 80 \mathrm{mg}, 13.7 \pm 11.5 \mathrm{ng} / \mathrm{mL}$; $120 \mathrm{mg}, 23.2 \pm 31.4 \mathrm{ng} / \mathrm{mL}$ ). For PK/safety analysis, the

A

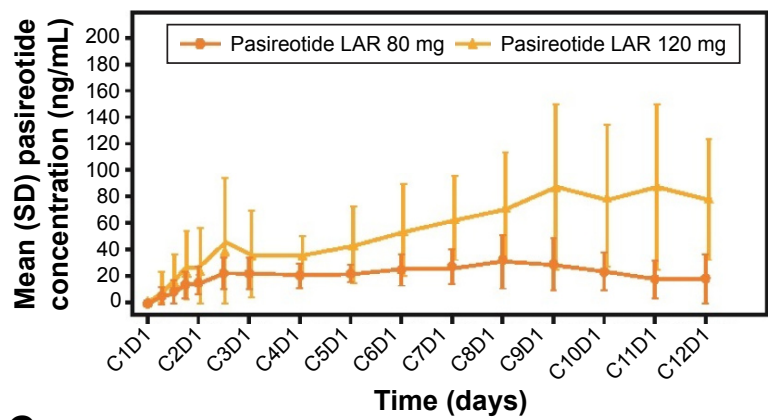

C

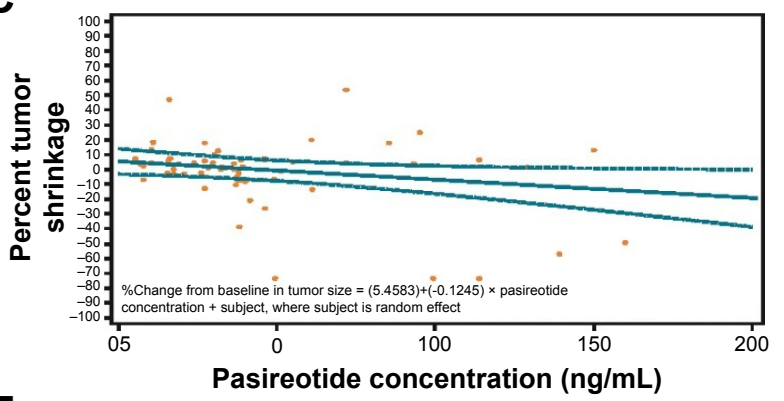

E

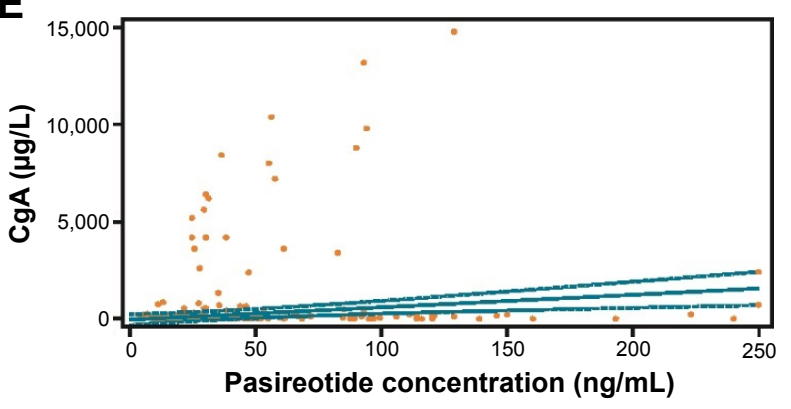

logistic regression analysis suggested that the probability of bradycardia (HR $<40 \mathrm{bpm}$ ) tends to increase with increasing pasireotide concentrations, although statistical significance was not reached (odds ratio [95\% CI] for a 1.5 -fold

B

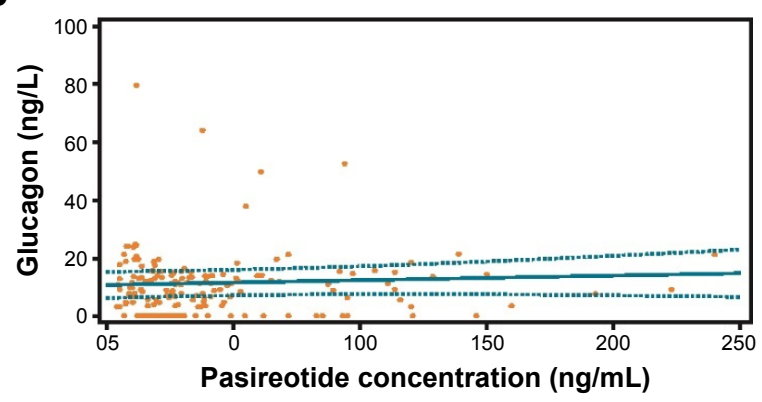

D

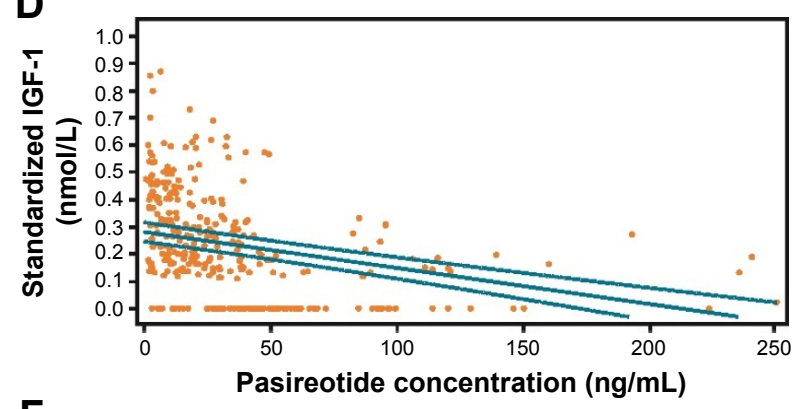

$\mathbf{F}$

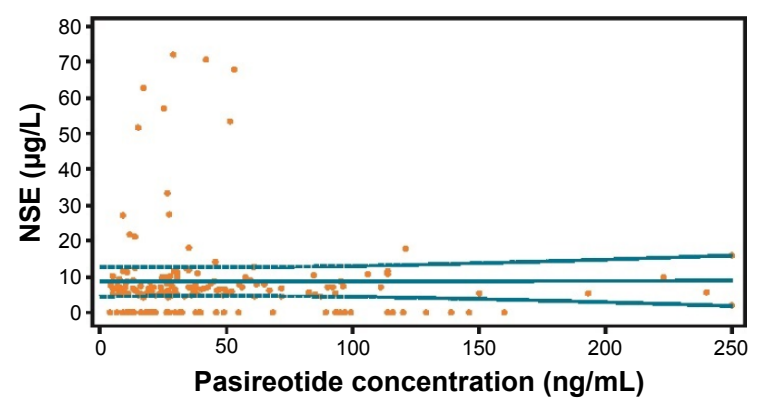

Figure 3 Results of the PK/pharmacodynamic analysis.

Notes: (A) Mean PK-concentration-time profiles from the PK analysis set. CxDy: Cycle x, Day y. Negative (mean - SD) values were truncated to zero. Below the LLOQ values $\left(<0.15 \mathrm{ng} / \mathrm{mL}\right.$ ) were set to zero. Day I pre-dose concentrations on $\mathrm{C} 2$ through $\mathrm{Cl} 2$ represent $C_{\min }$ concentrations; day 22 concentration from the $\mathrm{Cl}$ represents the $C_{\max }$ concentration. (B) Change from baseline tumor size vs pasireotide trough concentrations. (C) Change from baseline tumor size vs pasireotide trough concentrations. (D) IGF-I vs pasireotide trough concentrations. (E) CgA vs pasireotide trough concentrations. (F) NSE vs pasireotide trough concentrations.

Abbreviations: PK, pharmacokinetic; LLOQ, lower limit of quantitation; C2, Cycle 2; CI2, Cycle I2; CI, Cycle I; CgA, chromogranin A; NSE, neuron-specific enolase; LAR, long-acting release. 
increase in pasireotide concentration during day time [6 am through $10 \mathrm{pm}$ ]: 1.67 [0.38-7.34]; during night time [10 pm through $6 \mathrm{am}]: 2.02$ [0.49-8.29]). The thyroid-stimulating hormone (TSH) levels among five patients experiencing bradycardia ( $\mathrm{HR}<40 \mathrm{bpm}$ ) ranged from $0.8 \mathrm{mU} / \mathrm{L}$ at baseline to $7.91 \mathrm{mU} / \mathrm{L}$ at the last visit assessment; in four out of five patients, the levels were $<5 \mathrm{mU} / \mathrm{L}$ at the last visit. No significant association was observed between pasireotide concentrations and glucagon levels ( $P=0.42$; Figure $3 \mathrm{~B}$ ).

Regarding concomitant medications among patients with bradycardia (HR $<40 \mathrm{bpm}$ ), two patients were prescribed medication for hyperglycemia and hypertension, and one patient had intermittent heart blockage during the study for which a pacemaker was inserted.

In the PK/efficacy analysis, higher pasireotide concentrations appeared to have a weak correlation with higher percentage tumor shrinkage, and this trend did not achieve statistical significance (slope $=-0.012 ; P=0.08$; Figure $3 \mathrm{C}$ ). IGF-1 levels showed an expected decreasing trend with increasing pasireotide concentrations, which confirmed the biochemical suppression of IGF-1 in patients with advanced NETs (Figure 3D). There was no exposure-response relationship between NET-specific tumor biomarkers CgA and NSE levels and pasireotide concentrations (Figure 3E and F).

\section{Discussion}

This phase I study evaluated the MTD of pasireotide LAR in patients with advanced NETs with primary tumor sites, including the gastrointestinal (GI) tract, pancreas, and lung. No protocol-defined DLTs were reported in the study, and the
MTD was defined at $120 \mathrm{mg}$ for pasireotide LAR in patients with advanced NETs.

In a post hoc safety analysis, a higher incidence of bradycardia (HR < 40 bpm; five patients; $31 \%$ ) was observed in the $120 \mathrm{mg}$ dose group. Potential causes for this observation were investigated with respect to pasireotide concentrations and imbalances in hormone levels. In the PK analysis, higher pasireotide concentrations did suggest a moderate increase in risk of bradycardia (HR $<40 \mathrm{bpm}$ ); however, this observation was not statistically significant (Figure 4). Modulation of glucagon levels by pasireotide (a known effector of the cardiovascular axis and often used in treatment of bradycardia caused by beta-blockers ${ }^{23,24}$ ) doses was further examined as a potential cause of bradycardia ( $\mathrm{HR}<40 \mathrm{bpm}$ ). However, no clinically significant changes in the levels of glucagon were observed with increasing pasireotide concentrations. Bradycardia (HR $<40 \mathrm{bpm}$ ) thus appears to be a doselimiting effect; however, the mechanism and clinical significance remain uncertain and need further study. Incidence of bradycardia (HR $<40 \mathrm{bpm}$ ) at $120 \mathrm{mg}$ dose during the study was the reason not to test higher doses of pasireotide. Future studies could explore whether different dosing schedules could achieve higher exposure while minimizing bradycardia (HR $<40$ bpm).

Preliminary efficacy observations showed encouraging PFS and DCRs with pasireotide LAR in patients with advanced progressive NETs. In the preliminary assessment of tumor responses, pasireotide LAR showed evidence of antitumor activity as observed by the high rate of disease stabilization with both the $120 \mathrm{mg}$ and the $80 \mathrm{mg}$ doses in
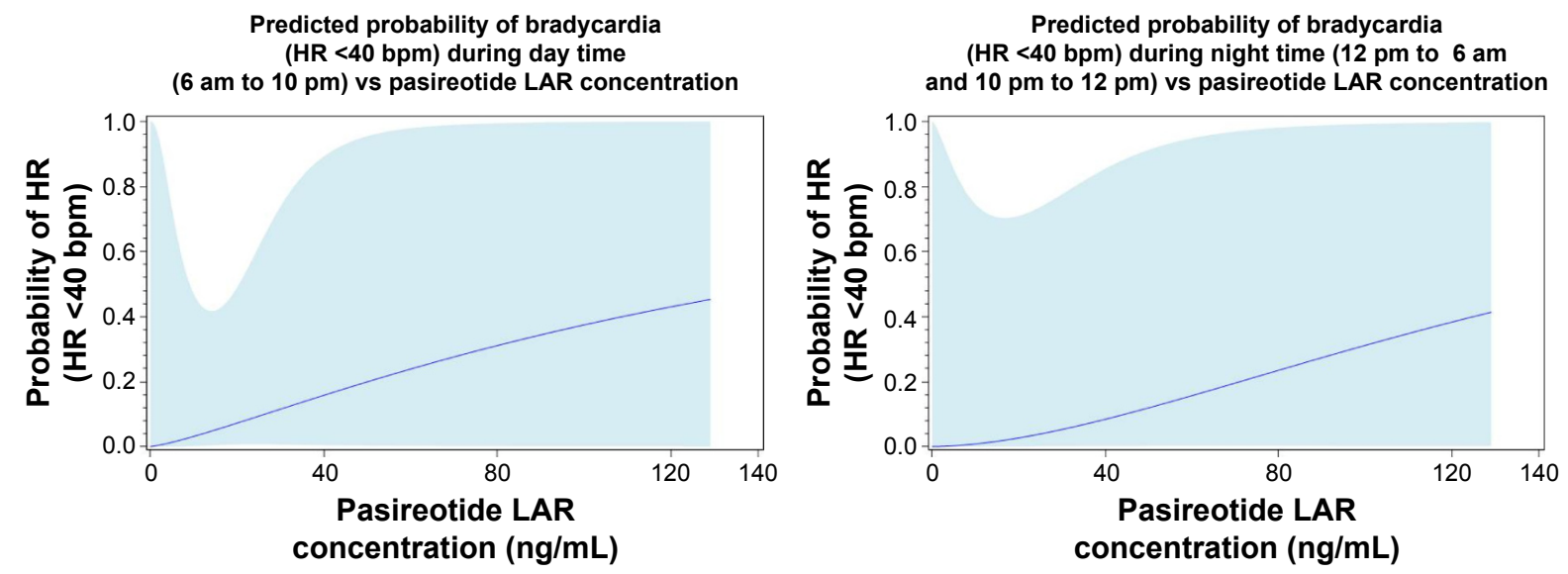

- Probability of HR (HR $<40 \mathrm{bpm}) \square 95 \% \mathrm{Cl}$

Figure 4 Predicted probability of bradycardia vs pasireotide LAR concentration.

Abbreviations: $\mathrm{Cl}$, confidence interval; LAR, long-acting release; HR, heart rate; bpm, beats per minute. 
this patient population. Although objective radiographic responses are rarely observed with SSAs, two PRs were observed among 16 patients in the $120 \mathrm{mg}$ cohort, providing further evidence of the promising antitumor efficacy of pasireotide LAR in patients with advanced NETs.

In the biomarker analysis, IGF-1, an established biochemical activity marker in pituitary tumors, ${ }^{25}$ and NET-specific tumor biomarkers $\mathrm{CgA}$ and $\mathrm{NSE}^{26,27}$ were further investigated to gain insights into the PKs of pasireotide LAR. As expected, pasireotide LAR showed a dose-dependent reduction in IGF-1 levels, confirming the biochemical suppression of IGF-1 in patients with advanced NETs. The levels of tumor burden markers $\mathrm{CgA}$ and NSE did not show any significant change, correlating with the SD seen in the majority of the patients upon pasireotide LAR treatment.

Furthermore, the phase II COOPERATE-2 study was conducted to assess the efficacy and safety of pasireotide (LAR; $60 \mathrm{mg} / 28$ days, IM) in combination with everolimus (10 mg/day, oral) in patients with advanced, well-differentiated, progressive pNETs. Although a benefit with regard to PFS was not observed in this study, an antisecretory effect associated with pasireotide was confirmed by the suppression of tumor growth factors IGF-1 and IGF-2 and corresponding regulation of the IGF-binding proteins IGFBP2 and IGFBP3. ${ }^{21}$

\section{Conclusion}

Pasireotide at a dose of $120 \mathrm{mg}$ every 4 weeks appears to show encouraging antitumor activity. The drug is generally well tolerated at this dose; however, the bradycardia $(\mathrm{HR}<40 \mathrm{bpm})$ rate of $31 \%$ represents a potential concern. The clinical significance of pasireotide-associated bradycardia (HR $<40 \mathrm{bpm}$ ) is unclear. Phase II studies evaluating pasireotide at a dose of $120 \mathrm{mg}$ are warranted in patients progressing on conventional SSAs.

\section{Acknowledgments}

We thank Anamika Gulati from Novartis Healthcare Pvt. Ltd. for providing medical editorial assistance and Christelle Darstein for her strong biostatistics analysis support. This study was funded by Novartis Pharmaceuticals Corporation. This paper was presented at the American Society of Clinical Oncology (ASCO) Annual Meeting 2016 as a poster presentation with interim findings as "Phase I, multi-center, open-label, dose-escalation study of pasireotide LAR (PAS) in patients with advanced neuroendocrine tumors (NET)," http://meetinglibrary.asco.org/content/169565-176.

\section{Disclosure}

JCY has received consulting or advisory fees from Ipsen, Lexicon, and Novartis and research funding from Novartis. MGK, KHR, KH, and SR are employees of Novartis. JRS has received honoraria from Novartis; consulting or advisory fees from Ipsen, Lexicon, and Novartis; and research funding from Novartis and Pfizer and is on the speaker's bureau for Bayer and Genentech. EMW has received consulting or advisory fees from Celgene, Ipsen, and Novartis. ACM is a member of the Speaker Bureau for Genentech. JAC has received consulting or advisory fees from Ipsen, Lexicon, Novartis, and Oxigene and has stock in Merck. The authors report no other conflicts of interest in this work.

\section{References}

1. Gardner-Roehnelt NM. Update on the management of neuroendocrine tumors: focus on somatostatin antitumor effects. Clin JOncol Nurs. 2012 16(1):56-64.

2. di Bartolomeo M, Bajetta E, Buzzoni R, et al. Clinical efficacy of octreotide in the treatment of metastatic neuroendocrine tumors. A study by the Italian Trials in Medical Oncology Group. Cancer. 1996;77(2): 402-408.

3. Oberg K. Management of neuroendocrine tumours. Ann Oncol. 2004;15(supp1 4):iv293-iv298.

4. Kvols LK, Moertel CG, O’Connell MJ, Schutt AJ, Rubin J, Hahn RG. Treatment of the malignant carcinoid syndrome. Evaluation of a longacting somatostatin analogue. N Engl J Med. 1986;315(11):663-666.

5. Rubin J, Ajani J, Schirmer W, et al. Octreotide acetate long-acting formulation versus open-label subcutaneous octreotide acetate in malignant carcinoid syndrome. J Clin Oncol. 1999;17(2):600-606.

6. Rinke A, Muller HH, Schade-Brittinger C, et al. Placebo-controlled, double-blind, prospective, randomized study on the effect of octreotide LAR in the control of tumor growth in patients with metastatic neuroendocrine midgut tumors: a report from the PROMID Study Group. J Clin Oncol. 2009;27(28):4656-4663.

7. Caplin ME, Pavel M, Cwikla JB, et al. Lanreotide in metastatic enteropancreatic neuroendocrine tumors. N Engl J Med. 2014;371(3):224-233.

8. Berardi R, Rinaldi S, Torniai M, et al. Gastrointestinal neuroendocrine tumors: searching the optimal treatment strategy - a literature review. Crit Rev Oncol Hematol. 2016;98:264-274.

9. Schmid HA, Schoeffter P. Functional activity of the multiligand analog SOM230 at human recombinant somatostatin receptor subtypes supports its usefulness in neuroendocrine tumors. Neuroendocrinology. 2004;80(supp1 1):47-50.

10. de Herder WW, Hofland LJ, van der Lely AJ, Lamberts SW. Somatostatin receptors in gastroentero-pancreatic neuroendocrine tumours. Endocr Relat Cancer. 2003;10(4):451-458.

11. Villaume K, Blanc M, Gouysse G, et al. VEGF secretion by neuroendocrine tumor cells is inhibited by octreotide and by inhibitors of the PI3K/ AKT/mTOR pathway. Neuroendocrinology. 2010;91(3):268-278.

12. Tulipano G, Stumm R, Pfeiffer M, Kreienkamp HJ, Höllt V, Schulz S. Differential beta-arrestin trafficking and endosomal sorting of somatostatin receptor subtypes. J Biol Chem. 2004;279(20): 21374-21382.

13. Cescato R, Schulz S, Waser B, et al. Internalization of sst2, sst3, and sst5 receptors: effects of somatostatin agonists and antagonists. $\mathrm{J} \mathrm{Nucl}$ Med. 2006;47(3):502-511.

14. Li M, Li W, Kim HJ, Yao Q, Chen C, Fisher WE. Characterization of somatostatin receptor expression in human pancreatic cancer using real-time RT-PCR. J Surg Res. 2004;119(2):130-137. 
15. Ronga G, Salerno G, Procaccini E, et al. 111 In-octreotide scintigraphy in metastatic medullary thyroid carcinoma before and after octreotide therapy: in vivo evidence of the possible down-regulation of somatostatin receptors. Q J Nucl Med. 1995;39(4 suppl 1):134-136.

16. Plockinger U, Wiedenmann B. Treatment of gastroenteropancreatic neuroendocrine tumors. Virchows Arch. 2007;451(suppl 1):S71-S80.

17. Schmid HA. Pasireotide (SOM230): development, mechanism of action and potential applications. Mol Cell Endocrinol. 2008; 286(1-2):69-74.

18. Chen X, Shen G, Jiang J, et al. Pharmacokinetics and safety of subcutaneous pasireotide and intramuscular pasireotide long-acting release in Chinese male healthy volunteers: a phase I, single-center, open-label, randomized study. Clin Ther. 2014;36(8):1196-1210.

19. Wolin EM, Jarzab B, Eriksson B, et al. Phase III study of pasireotide long-acting release in patients with metastatic neuroendocrine tumors and carcinoid symptoms refractory to available somatostatin analogues. Drug Des Devel Ther. 2015;9:5075-5086.

20. Cives M, Kunz PL, Morse B, et al. Phase II clinical trial of pasireotide long-acting repeatable in patients with metastatic neuroendocrine tumors. Endocr Relat Cancer. 2015;22(1):1-9.

21. Kulke M, Ruszniewski P, Van Cutsem E, et al. A randomized, openlabel, phase 2 study of everolimus in combination with pasireotide LAR or everolimus alone in advanced, well-differentiated, progressive pancreatic neuroendocrine tumors: COOPERATE-2 trial. Ann Oncol. Epub 2017 Mar 6.
22. Neuenschwander B, Branson M, Gsponer T. Critical aspects of the Bayesian approach to phase I cancer trials. Stat Med. 2008;27(13): 2420-2439.

23. Love JN, Howell JM. Glucagon therapy in the treatment of symptomatic bradycardia. Ann Emerg Med. 1997;29(1):181-183.

24. Bindon MJ, Barlotta K. Glucagon treatment for bradycardia and a junctional rhythm caused by excessive beta-blockade. Resuscitation. 2009;80(11):1327.

25. Singh B, Smith JA, Axelrod DM, et al. Insulin-like growth factor-I inhibition with pasireotide decreases cell proliferation and increases apoptosis in pre-malignant lesions of the breast: a phase 1 proof of principle trial. Breast Cancer Res. 2014;16(6):463.

26. Gut P, Czarnywojtek A, Fischbach J, et al. Chromogranin A - unspecific neuroendocrine marker. Clinical utility and potential diagnostic pitfalls. Arch Med Sci. 2016;12(1):1-9.

27. Baudin E, Gigliotti A, Ducreux M, et al. Neuron-specific enolase and chromogranin A as markers of neuroendocrine tumours. Br J Cancer. 1998;78(8):1102-1107.
OncoTargets and Therapy

\section{Publish your work in this journal}

OncoTargets and Therapy is an international, peer-reviewed, open access journal focusing on the pathological basis of all cancers, potential targets for therapy and treatment protocols employed to improve the management of cancer patients. The journal also focuses on the impact of management programs and new therapeutic agents and protocols on

\section{Dovepress}

patient perspectives such as quality of life, adherence and satisfaction. The manuscript management system is completely online and includes a very quick and fair peer-review system, which is all easy to use. Visit http://www.dovepress.com/testimonials.php to read real quotes from published authors. 